InOdia $\quad \begin{aligned} & \text { InMedia } \\ & \text { The French Journal of Media Studies }\end{aligned}$

7.1. $\mid 2018$

Visualizing Consumer Culture

\title{
Critical Clickbait: Artist Interventions in Commercial Visual Culture
}

Dawn Woolley

\section{(2) OpenEdition \\ 12 Journals}

\section{Electronic version}

URL: http://journals.openedition.org/inmedia/1444

DOI: 10.4000/inmedia.1444

ISSN: 2259-4728

\section{Publisher}

Center for Research on the English-Speaking World (CREW)

\section{Electronic reference}

Dawn Woolley, "Critical Clickbait: Artist Interventions in Commercial Visual Culture », InMedia [Online], 7.1. 2018, Online since 20 December 2018, connection on 08 September 2020. URL : http:// journals.openedition.org/inmedia/1444 ; DOI : https://doi.org/10.4000/inmedia.1444

This text was automatically generated on 8 September 2020

(C) InMedia 


\title{
Critical Clickbait: Artist Interventions in Commercial Visual Culture
}

\author{
Dawn Woolley
}

\section{Introduction}

1 I am an artist and consumer culture researcher. In my research I explore the relation between people and objects and the impact that images have as producers and disseminators of social values. I examine commodity packaging and adverts to determine the ideologies they support and to understand how they shape the identity of the consumer. In 1960 Raymond Williams identified this propensity of advertising, writing:

at an increasing rate, it has become involved with the teaching of social and personal values [...] Advertising is also, in a sense, the official art of modern capitalist society: it is what 'we' put up in 'our' streets and use to fill half of 'our' newspapers and magazines [...] Since this is the actual social status of advertising, we shall only understand it with any adequacy if we can develop a kind of total analysis in which the economic, social and cultural facts are visibly related. We may then also find, taking advertising as a major form of modern social communication, that we can understand our society itself in new ways. ${ }^{1}$

2 Advertisements are dominant in contemporary visual culture, and express information regarding the objects and values that are prized by society. Advertising images are also portraits of a type, evoking unseen subjects who possess and consume the objects on display. Drawing on both definitions of the term 'consume' I use food still life artworks to represent different characters and positions in relation to advanced capitalist society. What I eat and how I eat is a metonym of my wider consumer habits. Food is also employed as a metaphor for the subjection of my body under capitalist systems. The commodities I consume are integrated in my identity and my identity is shaped to a marketing demographic. I am what I consume. I am an advertisement for the 
commodities I consume. The still life artworks that I produce examine the social ideals that are reinforced through the consumption of commodities.

In my research, photography is as much a subject as a medium. I produce site-specific art works for commercial advertising spaces on billboards and social networking sites. The artworks are interventions: it is my intention to present images that disrupt the repetitious order of consumerism, providing a space in which the viewer can critically consider contemporary consumer society. I achieve this using methods of destabilisation described by Walter Benjamin. In The Arcades Project Benjamin says that surrealist montages can work as dialectical images because montage "interrupts the context into which it is inserted," ${ }^{2}$ causing instability and ambiguity. By disrupting the value attributed to commodities, Benjamin said consumers can appropriate commodities as emancipatory wish images:

if the social value (hence the meaning) of commodities is their price, this does not prevent them from being appropriated by consumers as wish images within the emblem books of their private dreamworld [...] once the initial hollowing out of meaning has occurred and a new signification has been arbitrarily inserted into it, this meaning 'can at any time be removed in favor of any other.' ${ }^{3}$

By producing artworks to be displayed in commercial advertising spaces, it is intended that they interrupt the context into which they are inserted and momentarily disrupt the dominant social values that are ordinarily expressed in those spaces.

\section{Pacifier Billboard}

5 To intervene in the visual landscape increasingly dominated by advertising I developed a series of site-specific art works that were displayed in billboard advertising spaces (with the financial support of a grant from the Arts Council of Wales). The posters are collectively titled Consumer and use the tropes and styles of advertising to encourage people to think about the contradictions of capitalist consumption. Pacifier implies that consumption is a distraction, particularly the body-labour and commodification that aims to improve the surface appeal of the female body. Overt sexualisation and infantilisation are implied by the sweets, sex toys, and nail art practice dummies that are depicted in the photographs. The name pacifier refers to the dummy shaped sweets featured in a number of the images and to the original meaning of the term pacificare 'to make peace; to allay the anger of someone.' However, pacify has also come to suggest submission and terrorization, evoking a more predatory and aggressive from of consumer culture. In reference to the differing forms of pacification described above, the vignettes in Pacifier can be read in terms of portraiture or, more disturbingly, as hunting trophies.

6 The Pacifier billboard also includes the following quotation from Brave New World by Aldous Huxley: "the decanted infant howls; at once a nurse appears with a bottle of external secretion. Feeling lurks in that interval of time between desire and its consummation. Shorten that interval [...]." In Huxley's dystopian society, external secretion is used to pacify infants as soon as they experience hunger. The quote suggests that consumers will only feel lack or want if gratification is delayed. In the novel, shopping and commoditised leisure activities are instrumentalised as a counterrevolutionary force because preoccupied consumers are unlikely to want to change society. 


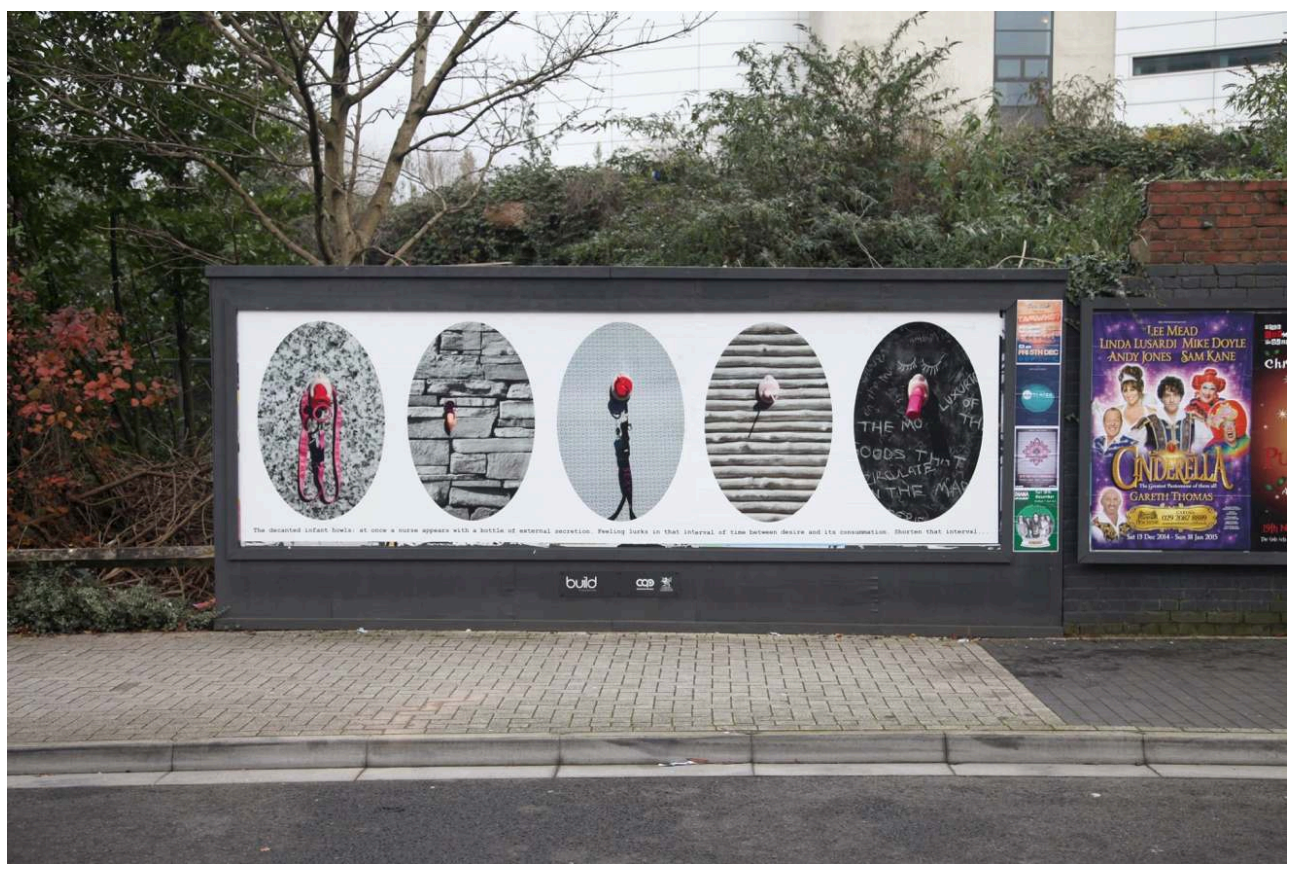

Figure 1 Dawn Woolley, Pacifier, billboard poster, Cardiff, 2014 (supported by the Arts Council of Wales.

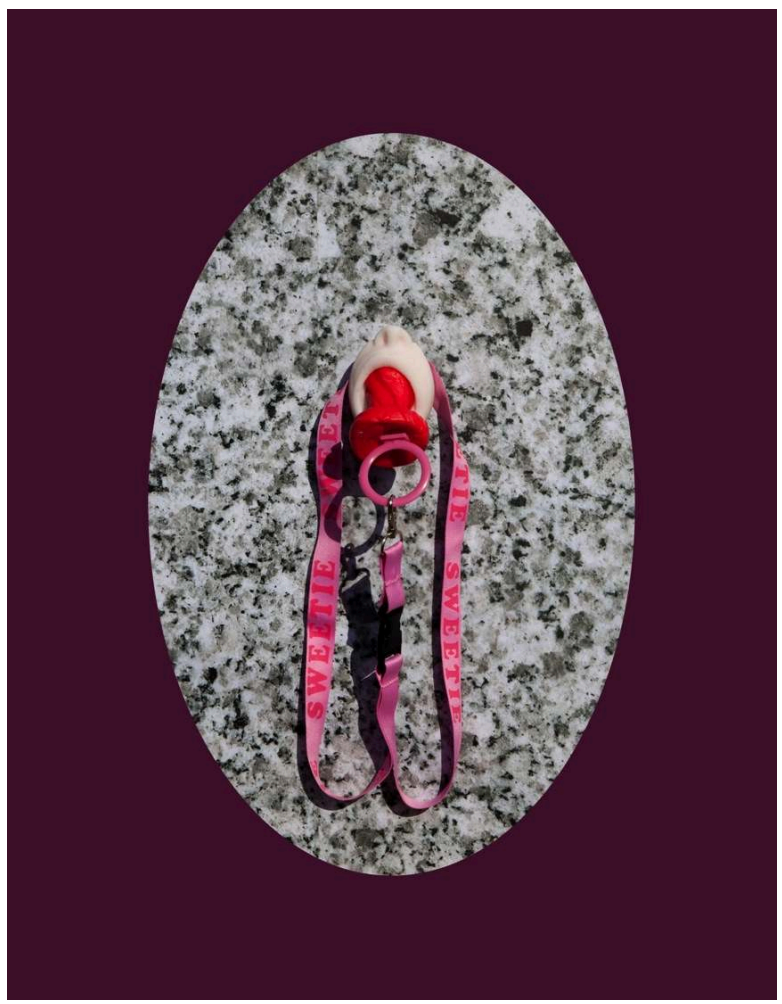

Figure 2 Dawn Woolley, Pacifier (01) digital photograph mounted on MDF, 2014,70cm x 55cm. 


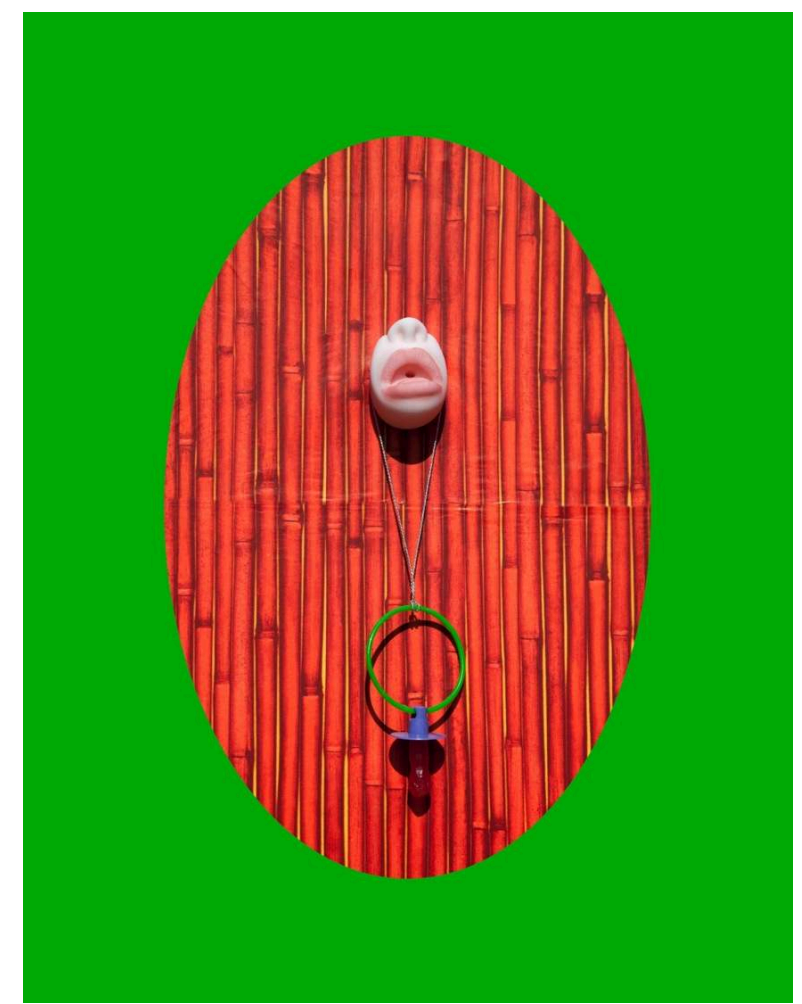

Figure 3 Dawn Woolley, Pacifier (05) digital photograph mounted on MDF, 2014, 70cm x 55cm.

\section{Hysterical Selfies}

7 Contemporary social relations are mediated, and often dominated by online social networks. I have come to view these sites as the contemporary commercial space where commodity culture pervades social existence. In my online social interactions the fetishism of commodities is fully articulated; what appear to be interactions between people are actually interactions between commodities. For a short period of time I produced selfies and shared them online accompanied by \#selfie. As I browsed the \#selfie newsfeed I found that the term 'selfie' is used to advertise self-improvement products, suggesting there is no distinction between the commodity and the body that uses it; they are one object. The mode of identification is direct and forceful, the commodity is you and you are it, there is no escape from this consumer relation. The repetitive layout of images on instagram, twitter and facebook reinforce equivalence between body and commodity, obliterating the hierarchy between consumer and consumed.

8 In response to these findings I produced a series of still life images called Hysterical Selfies. Each still life is photographed from a standing position and features a mirror, conforming to the framing conventions of mirror selfies. However, the mirrors do not reflect an individual posing with a camera, but reveal more commodities suggestive of an identity formed entirely by products and advertising concepts. Each image is printed on a commercial "pop-up banner," further emphasising the commercial origin of the subject's identity. It is my intention to emphasise how the ideological values of commodities accumulate and impact on the consumer. The commodities in the Hysterical Selfies are grouped by the ideological value they share and the hyperbolic 
gender stereotypes they reinforce. For example, a space that looks like a gym contains fitness and body-building products called Grenade, Fierce Domination, and Monster Assault (Figure 5.). Masculinity, fitness, strength, and violence are collapsed into this idealized masculine identity. Another room is decorated with faux-fur print wallpaper and showcases a plethora of products such as Black Cherry Body Yoghurt, 2000 Calorie Mascara, and "Bite Me" Pyjamas designed to make the wearer look like dessert (Figure 6.). Each product evokes ideas of indulgent eating but the packaging always bears the warning "do not consume," "for external use only." For female consumers in particular, the message is "consume but do not eat." By grouping the products in this manner, their ideological messages become apparent, as does the type of consumer behaviour idealised by the products. It is my intention to draw attention to the ideas and ideals that are attached to products in advertisements, in order to show that they reinforce social norms and acceptable gendered behaviour.

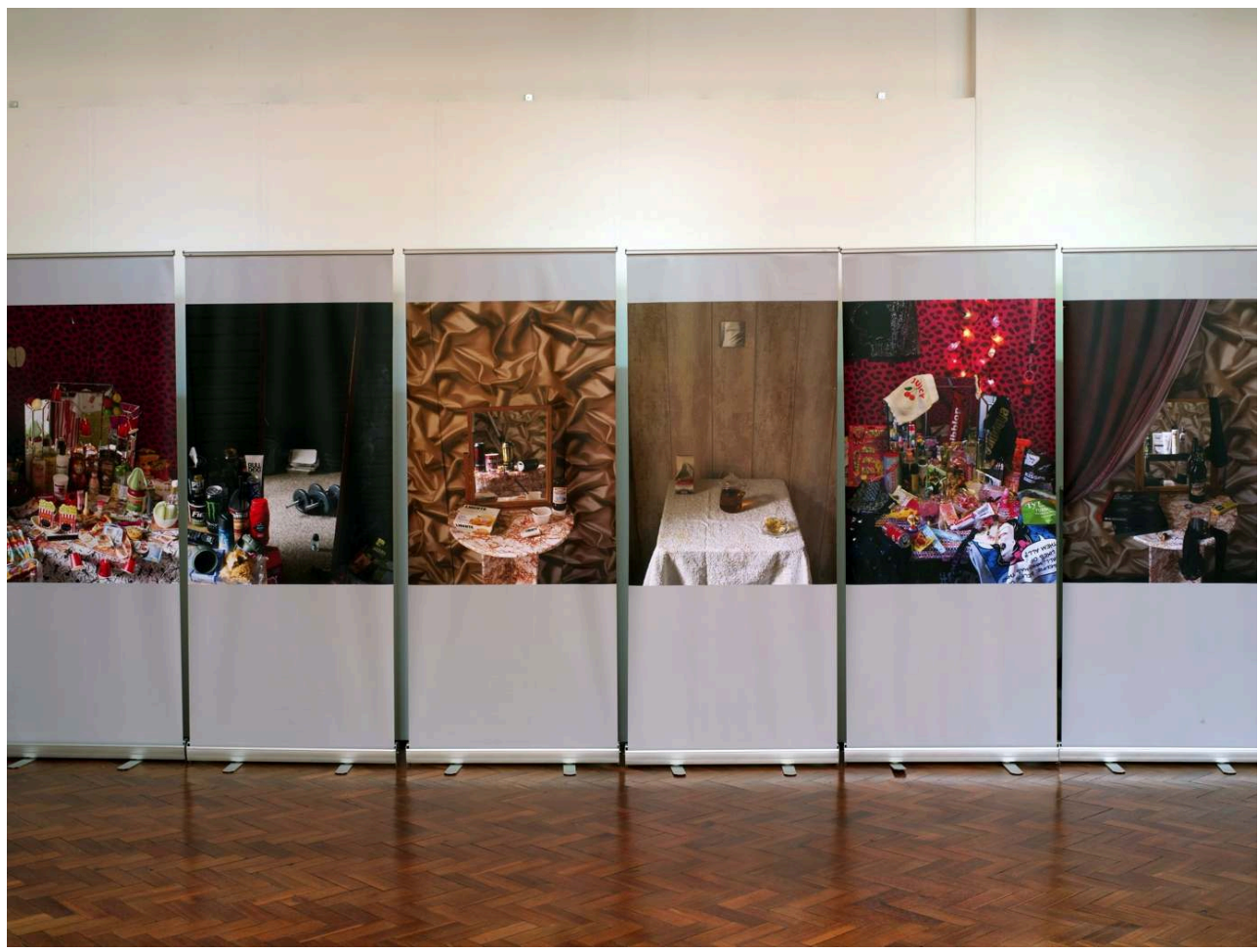

Figure 4 Dawn Woolley, Hysterical Selfies, pop-up display banners, $80 \mathrm{~cm}$ x 200cm, Ruskin Gallery, Cambridge, 2017. 


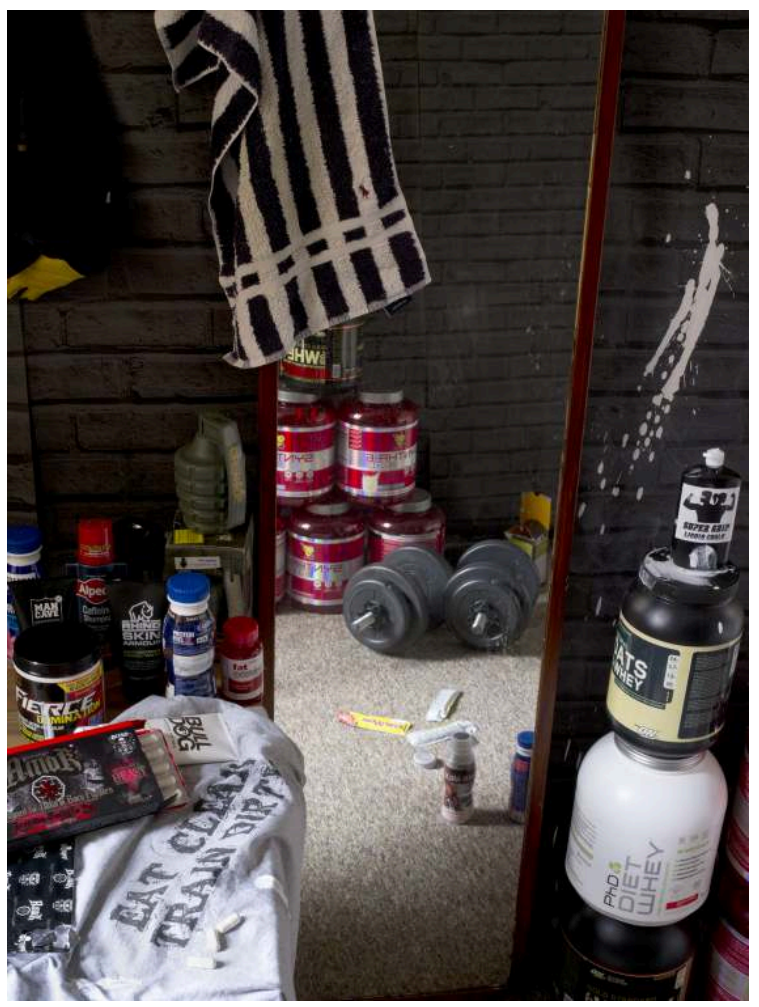

Figure 5 Dawn Woolley, Hysterical Selfie (Super Grip), pop-up display banner, 2015.

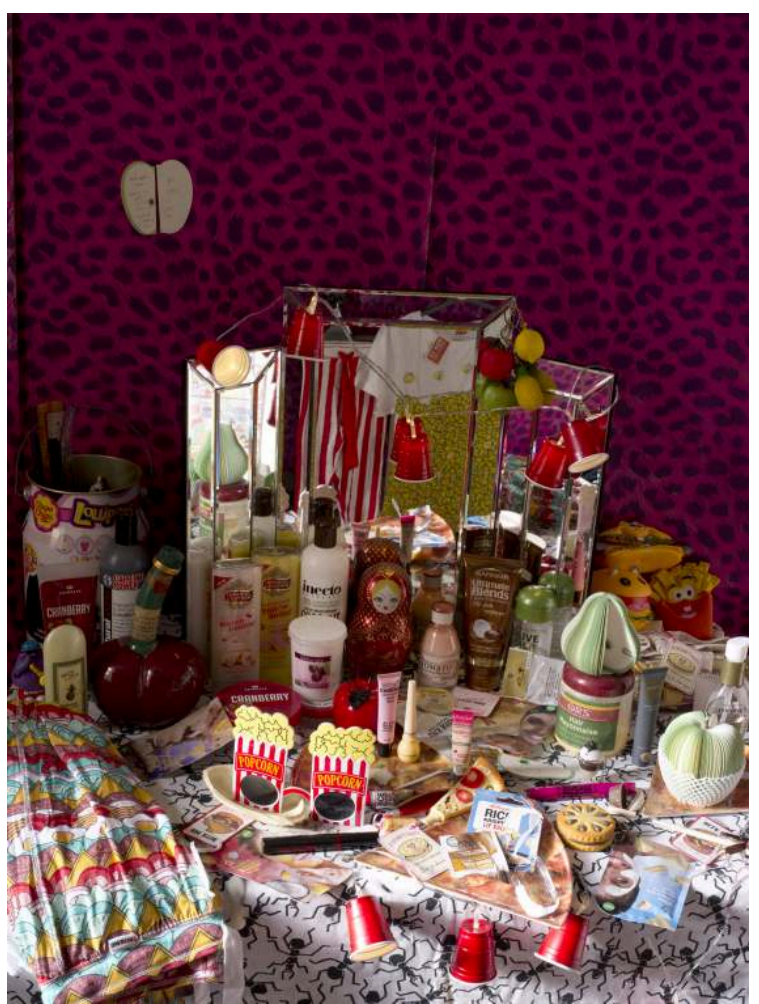

Figure 6 Dawn Woolley, Hysterical Selfie (Bite Me), pop-up display banner, 2015. 


\section{Wishbook}

As I gathered commodities for the hysterical selfies series, I was confounded by some of the product names and advertising slogans. I wanted to make work that more overtly revealed the ideological values of the commodities, so I presented individual commodities in a site-specific project on Instagram. I chose to present the work online to enable me to draw attention to the use of \#selfie as a method for product placement in social networking site newsfeeds. The title of this work derives from nineteenthcentury commodity catalogues such as The Great Wish Book and American Dream Book, selling the American way of life and a homogenised version of culture. The title also alludes to Benjamin's idea that by changing the social value of commodities consumers are able to inhabit the objects and make them act abnormally. In Wishbook I aim to question the ideological meaning attributed to the commodities by exaggerating and contradicting the values they express.

The commodities are scanned and posted on Instagram accompanied by hashtags that are positive and promotional in some instances, and negative and critical in others. By presenting the commodity in isolation against a white background the images mimic an advertising aesthetic. However, the Wishbook commodities are represented by empty packaging or half-eaten food, and the white background shows the residues and stains from previous commodities. In Wishbook the commodities are simultaneously a desired commodity and disregarded rubbish. The images look like poor quality adverts or the contents of a bin, and the hashtags read like bad poetry. The Instagram account functions as an online commodity catalogue and through the use of hashtags the posts also exist in a variety of newsfeeds, disrupting the context in which they are inserted. The posts appear among adverts and behave abnormally.

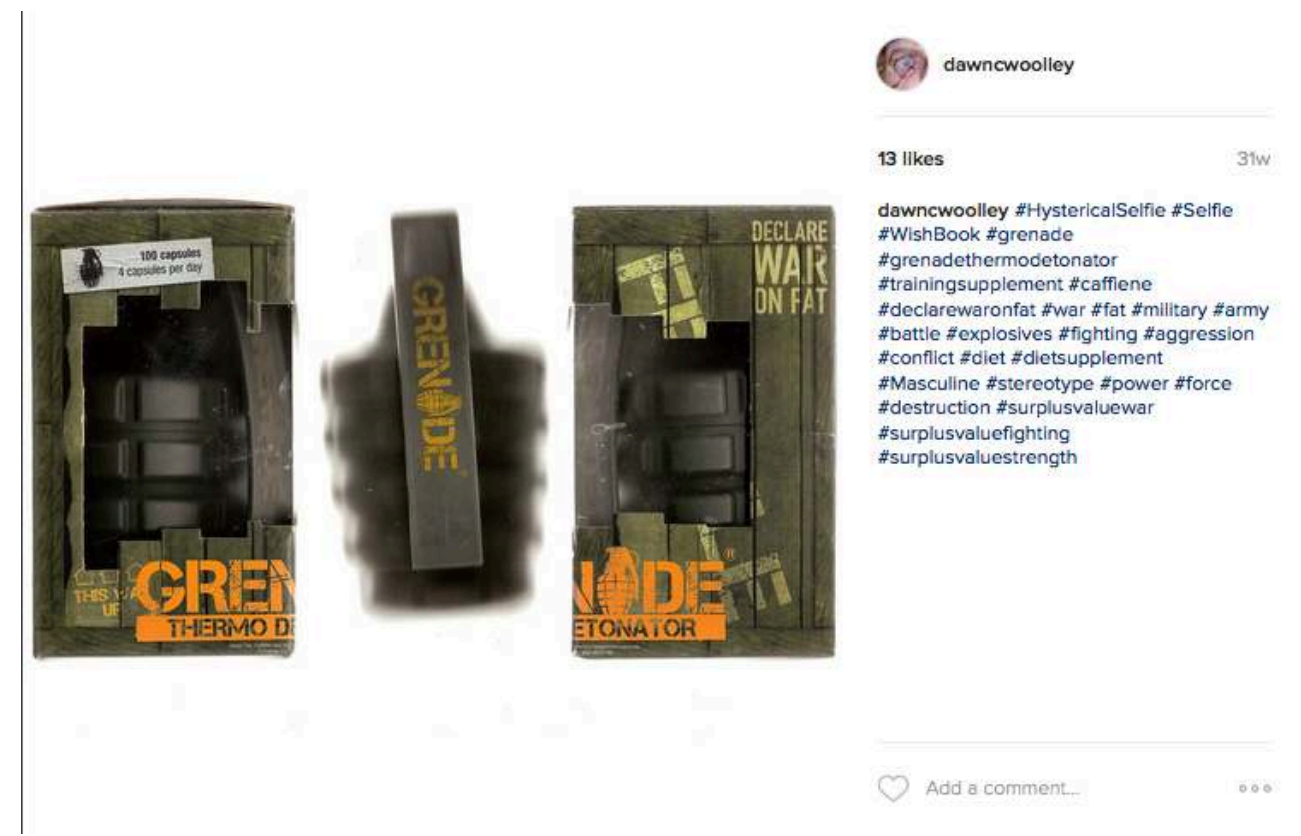

Figure 7 Dawn Woolley, Wishbook (Grenade), images and hashtags posted on Instagram, 2015-18, https://www.instagram.com/dawncwoolley/. 


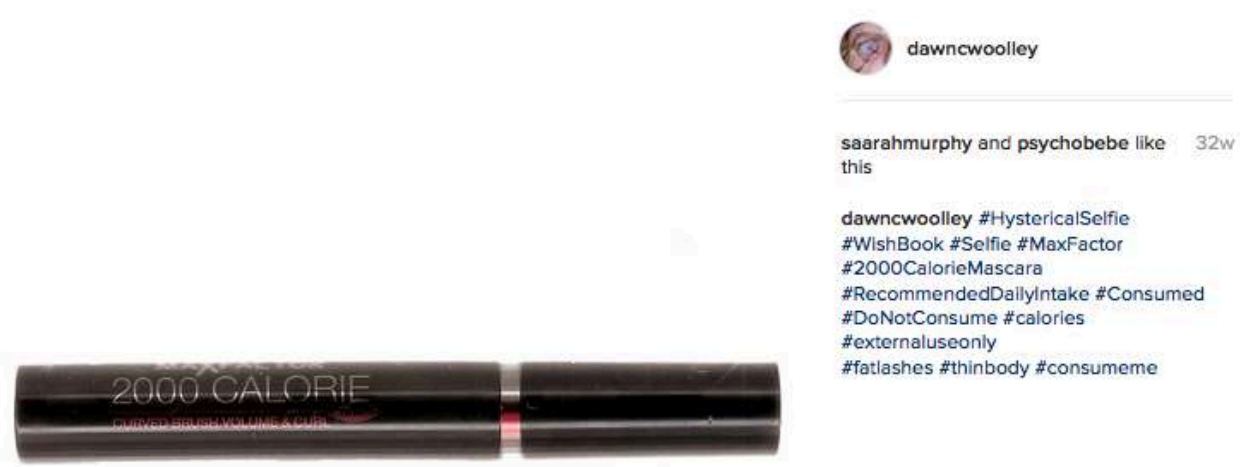

Figure 8 Dawn Woolley, Wishbook (2000 Calorie Mascara), images and hashtags posted on Instagram, 2015-18, https://www.instagram.com/dawncwoolley/.

\section{BIBLIOGRAPHY}

Buck-Morss, Susan. The Dialectics of Seeing: Walter Benjamin and the Arcades Project. Cambridge, MA: MIT Press, 1991.

Huxley, Aldous. Brave New World. London: Vintage, 2007 (1932).

Williams, Raymond. Culture and Materialism, London : Verso, 2005 (1960).

\section{ENDNOTES}

1. Raymond Williams, Culture and Materialism, (London : Verso, 2005), 2nd edn. 184-5.

2. Walter Benjamin, quoted in Susan Buck-Morss, The Dialectics of Seeing: Walter Benjamin and the Arcades Project (Cambridge, MA: MIT Press, 1991), 67.

3. Benjamin, quoted in Buck-Morss, The Dialectics of Seeing, 181-2.

4. Aldous Huxley, Brave New World (1932: London: Vintage, 2007), 37.

\section{ABSTRACTS}

In my research I explore the relation between people and objects, and the impact that images have as producers and disseminators of social values. I examine commodity packaging and adverts to determine the ideologies they support and to understand how they shape the identity 
of the consumer. To intervene in this process, I produce site-specific art works for commercial advertising spaces on billboards and social networking sites. This article will present a selection of artworks that aim to visualize the how consumer culture informs and influences identities and gendered behaviours.

INDEX

Keywords: Art, Capitalism, Commodities, Advertising, Selfies, Social Networking Sites, Marxism.

\section{AUTHOR}

\section{DAWN WOOLLEY}

Dawn Woolley is a visual artist and research fellow at Leeds Arts University. She completed an MA in Photography (2008) and PhD by project in Fine Art (2017) at the Royal College of Art. Recent exhibitions have included: "Self/Selfie", Ballarat International Foto Biennale, Australia (2017); "Le Féminin" Circulation(s), Arles (2017) and "Basically. Forever"; Tokyo Metropolitan Museum of Photography (2014). Solo exhibitions include; "Consumed: Stilled Lives" Blyth Gallery, London (2018), Ffotogallery, Cardiff (2018), Ruskin Gallery, Cambridge (2017), and Dyson Gallery, London (2016); "Visual Pleasure", Hippolyte Photography Gallery, Helsinki, Finland (2013) and Vilniaus Fotografijos Galerija, Lithuania (2012). Her forthcoming book, Consuming the Body: Capitalism, Social Media and Commodification, will be published in 2019 by I.B.Tauris. 